\title{
AVALIAÇÃO DA EXPRESSÃO DA CASPASE-3 NO ADENOCARCINOMA COLORRETAL ATRAVÉS DE UM SISTEMA COMPUTADORIZADO DE ANÁLISE DE IMAGEM
}

\section{Evaluation of caspase-3 markers expression in colorectal adenocarcinoma by a computadorized image analysis system}

\author{
Monres José GOMES, Jurandir Marcondes RIBAS-FILHO, Osvaldo MALAFAIA, \\ Nicolau Gregori CZECZKO, Carmen Australia Paredes Marcondes RIBAS, \\ Paulo Afonso Nunes NASSIF, Leandra Pauletto Muniz BITTENCOURT
}

ABCDDV/586

Gomes MJ, Ribas-Filho JM, Malafaia O, Czeczko NG, Ribas CAPM, Nassif PAN, Bittencourt LPM. Avaliação da expressão do Caspase-3 no adenocarcinoma colorretal através de um sistema computadorizado de análise de imagem. ABCD Arq Bras Cir Dig 2008;21(1):33-7

RESUMO - Racional - O câncer colorretal é uma das causas mais comum de mortes por neoplasias malignas no mundo ocidental, sendo que o adenocarcinoma colorretal representa mais de $90 \%$ dos tumores malignos que acometem o intestino grosso. A cisteíno-protease caspase-3, uma das mais participantes enzimas do processo apoptótico, pode ser utilizado como marcador tumoral. Objetivo - Identificar e quantificar a expressão da caspase-3 em amostras de adenocarcinomas colorretais através de um sistema computadorizado de análise de imagem, bem como correlacionar a expressão deste marcador. Métodos - Foi estudada por imunoistoquímica a proteína caspase- 3 em 55 amostras de adenocarcinoma colorretal parafinizadas. Para analisar os tecidos imunomarcados, o sistema SAMBA 4000 foi utilizado. Avaliaram-se as lâminas com o programa IMMUNO 4.00 através da leitura de 8 a 10 campos, determinando-se dois parâmetros: índice de marcagem (LI, Labeling Index) que descreve a porcentagem de área tecidual especificamente marcada pela prova imunoistoquímica, e a densidade óptica média (MOD, Mean Optical Density), a qual representa a intensidade de coloração do tecido medida por pixels positivos. Para a análise estatística, utilizou-se o teste t-Student e o coeficiente de Pearson para verificar a existência de correlação entre índice de marcagem e a densidade óptica média do mesmo marcador. Resultados - Todas as amostras estudadas apresentaram positividade à caspase-3 (LI médio: 85,24\% \pm 8,71\% de células positivas). Houve correlação estatisticamente significante entre o índice de marcagem e a densidade óptica média deste marcador. Conclusão - A intensidade da expressão de caspase-3 e o número de células expressando este marcador correlacionam-se positiva e significantemente.

DESCRITORES - Adenocarcinoma colorretal. Ki-67. Caspase-3. SAMBA 4000.

\section{INTRODUÇÃO}

O câncer colorretal (CCR) apresenta incidência variável nos diferentes países, predominando naqueles mais desenvolvidos. Incidências menores são registradas na América do Sul, sudoeste da Ásia, África equatorial e Índia. Nos EUA, é a segunda maior causa de morte por câncer, desconsiderando-se o sexo ${ }^{8}$, estimando-se o surgimento aproximado de 145 mil novos casos de câncer e mais de 56 mil mortes causadas por este tumor no ano de 2005 naquele país?

Com o aumento da expectativa de vida do povo brasileiro e com a progressiva industrialização e globalização, as neoplasias ganharam importância crescente no perfil de mortalidade do país, ocupando o segundo lugar como causa de óbito ${ }^{11}$. As estimativas de incidência de câncer no Brasil para 2006 apontam o CCR como o $5^{\circ}$

Trabalho realizado no Instituto de Pesquisas Médicas do Hospital Universitário Evangélico de Curitiba / Faculdade Evangélica do Paraná. Curitiba - PR - Brasil

Endereço para correspondência: Monres José Gomes E-mail: ipem@evangelico.org.br tumor maligno mais freqüente entre homens (com 11.390 casos novos) e $4^{\circ}$ entre as mulheres ( 13.970 casos novos). Apesar das indiscutíveis melhorias nas práticas médicas e cirúrgicas, a taxa de mortalidade por CCR pouco se alterou nos últimos 40 anos e a sobrevida global após cinco anos se mantém em cerca de $40 \%{ }^{6}$.

A aplicação clínica dos conhecimentos obtidos pelos estudos de genética molecular visando identificar pacientes sob risco, o desenvolvimento de estratégias de intervenção dietética e, sobretudo, os programas de rastreamento em indivíduos com risco aumentado para CCR representam caminhos a serem percorridos visando diminuir a mortalidade.

Mecanismos genético-moleculares têm sido implicados na tumorigênese e progressão dos cânceres. Tais mecanismos se originam na biologia molecular, que por sua vez se inicia com o estudo do ciclo celular. Este consiste em complexa cadeia de eventos metabólicos cujo objetivo é a duplicação da célula. A proliferação celular, assim como a apoptose e a angiogênese, tem forte correlação com a intensidade da carcinogênese.

Muitos marcadores biológicos têm sido avaliados de 
forma retrospectiva em pacientes com câncer de cólon a fim de determinar características prognósticas. Alguns destes biomarcadores estão sendo investigados e correlacionados como verdadeiros preditores de sobrevida. Os marcadores da apoptose, tipo proteína 32, protease da cisteína ou caspase-3, são responsáveis tanto parcial como totalmente pela clivagem proteolítica de muitas proteínas ${ }^{4}$. Com a informatização dos métodos de imagem, a técnica de SAMBA (Systeme d'Analyse Microphotometrique a Balayage Automatique) é atualmente uma das utilizadas para avaliação de quantificação da imunoistoquímica ${ }^{10}$.

A elucidação completa dos mecanismos genéticos envolvidos na patogênese molecular do CCR é fator de grande relevância na busca da diminuição tanto da mortalidade desta doença, quanto no impacto social por ela imposto, e com o conhecimento obtido através da genética avançada, é possível desenvolver métodos, investigar e identificar marcadores prognósticos de carcinoma colorretal para permitir decisões terapêuticas mais precisas aos pacientes acometidos.

Com base nestas considerações preliminares elaborouse a presente pesquisa, que tem como objetivo identificar e quantificar a expressão da caspase- 3 em amostras de adenocarcinomas colorretais através de um sistema computadorizado de análise de imagem, bem como correlacionar a expressão deste marcador

\section{MÉTODOS}

O presente estudo foi realizado no Instituto de Pesquisas Médicas (IPEM) do Hospital Universitário Evangélico de Curitiba/Faculdade Evangélica do Paraná e no Laboratório de Citologia e Histologia Ltda - CITOLAB, em Curitiba - PR - Brasil. Ele foi avaliado e aprovado pelo Comitê de Ética em Pesquisa da Sociedade Evangélica Beneficente.

As amostras que constituíram a casuística deste estudo foram selecionadas entre aquelas que apresentaram confirmação diagnóstica através de critérios histológicos de adenocarcinoma de cólon, e estavam adequadas para a realização da técnica de imunomarcagem. O número total de blocos disponibilizados foi de 60. Entretanto, apenas 55 apresentavam laudo confirmatório e material adequado para estudo imunoistoquímico. Foram confeccionadas 60 lâminas com a técnica de imunoistoquímica para caspase3, destas, foram lidas pelo Sistema IMMUNO 4.00, 19 lâminas.

Todos os tumores estavam identificados e processados de acordo com técnicas histológicas de rotina e emblocados em parafina de acordo com as descrições técnicas de Bancroft e Stevens ${ }^{2}$. Cada bloco foi submetido à nova microtomia para obtenção de novos cortes com espessura de $3 \mu \mathrm{m}$. A seguir, foram corados com a técnica de hematoxilina e eosina $(\mathrm{H} / \mathrm{E})$ e reavaliados independentemente por dois patologistas para se obter a confirmação do laudo histológico efetuado previamente. Os casos em que não houve concordância total entre os dois observadores foram submetidos à avaliação por outro patologista.
A imunoexpressão da caspase-3 foi obtida através do método imunoenzimático da streptoavidina-biotina-peroxidase.

Utilizou-se para caspase-3 (código A3537, Dako) - anticorpo policlonal de coelho anti-CPP32 humano. O aspecto histológico na avaliação imunoistoquímica está representado na Figura 1.

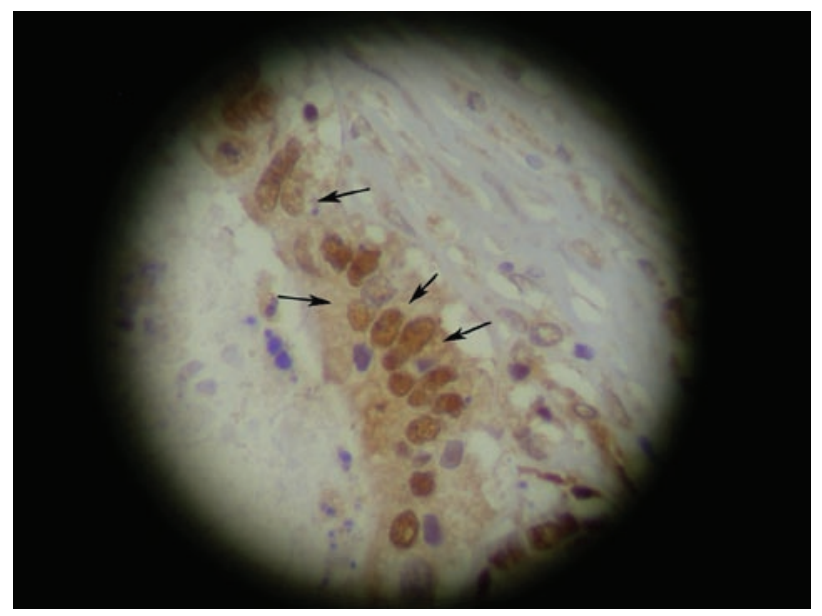

FIGURA 1 - Imunoistoquímica para caspase-3 onde ela apresenta marcação predominante no citoplasma (setas)

O estudo imunoistoquímico convencional foi realizado utilizando-se microscópio óptico NIKON ${ }^{\circledR}$ com aumento de 100 a 400 vezes.

$\mathrm{Na}$ análise quantitativa da imunoistoquímica foi utilizado o sistema SAMBA $4000^{\circledR}$ (Sistema de análise microscópica de busca automática), desenvolvido pela Alcatel (Grenoble - França). Imagens microscópicas são captadas por hardware e interpretadas por softwares especiais.

O microscópio utilizado no estudo foi da marca Axioskop ${ }^{\circledR}$ (Zeiss/Alemanha). Um potenciômetro que avalia com precisão a quantidade de luz, controla o fluxo luminoso oriundo da lâmpada de xenônio. Este feixe atravessa o condensador, a lâmina histológica, a objetiva em uso e então, é separado em duas partes: uma via destinada à observação visual através da ocular do microscópio e a outra à captação da imagem, por câmera de vídeo, a qual é enviada ao monitor acoplado ao computador.

As cores verde, azul e vermelha são padronizadas de forma que o sistema trabalha com o mesmo nível de captação previamente determinado, isto é, conseguido através da câmera de vídeo DXC-970M3CCD ${ }^{\circledR}$ (Sony/Japão). Um computador contendo o software IMMUNO $4.00^{\circledR}$ do sistema SAMBA 4000 analisou as imagens numerizadas. Elas são obtidas através da transformação das imagens analógicas, tais quais são percebidas, e que são captadas pela câmera.

Esta análise tem por finalidade transformar as imagens coradas pelo marcador em matriz numérica e, a partir dela, calcular parâmetros matemáticos que permitam a análise numerizada das imagens microscópicas.

As imagens processadas pelo sistema computadorizado 
são digitalizadas em ponto-imagem (pixel). Este processo confere um valor para cada ponto-imagem. A luz absorvida pelo tecido em cada segmento é quantificada. A quantificação da luz absorvida é expressada através de uma escala de variações de níveis de cinza que vai do 0 (preto) ao 255 (branco). Este processo corresponde a numerização da imagem, que envolve duas etapas: geração da matriz em tons de cinza e transformação desta em matriz numérica binária ${ }^{13}$.

Para otimização do aproveitamento das imagens em cada lâmina, seguiu-se a metodologia de rastreamento dos campos visuais com o procedimento de leitura sendo realizado em hot spots (Figura 2).

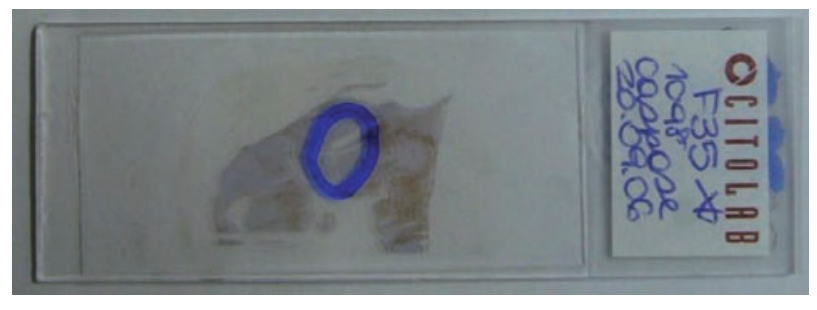

FIGURA 2 - Representação de um hot spot delineado na área com círculo

O total de superfícies examinadas variou de 60000 a $120000 \mu \mathrm{m}^{2}$. O tempo de leitura para cada lâmina foi de aproximadamente 40 minutos.

O software IMMUNO 4.00 foi utilizado para leitura e nas áreas selecionadas gerou-se dois parâmetros quantitativos de coloração imunoistoquímica: índice de marcagem (LI, Labeling Index) e densidade óptica média (MOD, Mean Optical Density).

O LI descreve a porcentagem de área tecidual especificamente marcada pela prova imunoistoquímica. A MOD denota a intensidade de coloração de forma proporcional, medida por pixels positivos e expressada em número absoluto.

Uma lâmina considerada controle-negativo, na qual o marcador caspase-3 é omitido, é utilizada para padronizar o sistema de análise microscópica computadorizada de imagens, e os parâmetros já descritos são analisados.

Após a análise dos parâmetros estabelecidos pelo SAMBA 4000 utilizou-se os programas Microsoft Excel para a criação do banco de dados, e Statistical Package for Social Science (SPSS) 11.5 para a realização dos cálculos estatísticos.

O nível de significância foi fixado em 5\%. Utilizou-se o teste t-Student assim como o coeficiente de Pearson para verificar a existência de correlação entre as variáveis LI e MOD da caspase-3.

\section{RESULTADOS}

Para o LI, sete lâminas foram analisadas que apresentaram 85 a $90 \%$ de células positivas $(36,84 \%)$. Quatro lâminas apresentaram 70 a $75 \%$ ou 95 a 100\% de células positivas (21,05\%), em ambos os casos (Gráfico 1).

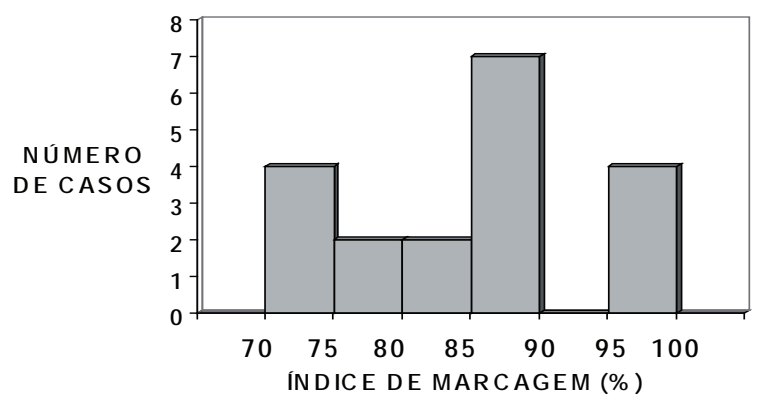

GRÁFICO 1 - Distribuição do índice de marcagem para caspase-3

Para a MOD, parte das lâminas apresentou pontuação de 45 a $50(31,58 \%, n=6)$, vindo em seguida o intervalo 30 a $35(21,05 \%, n=4)$ (Gráfico 2).

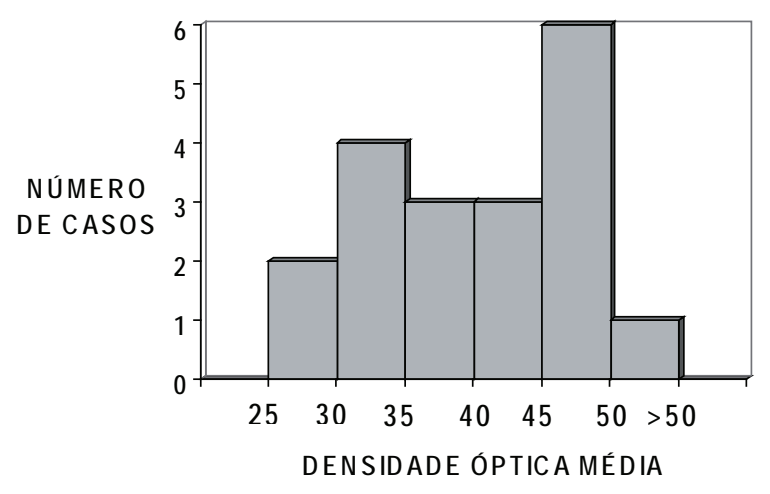

GRÁFICO 2 - Distribuição da densidade óptica da caspase-3

Na correlação entre as variáveis o coeficiente de correlação de Pearson demonstrou correlação estatisticamente significante entre o LI e a MOD $(P=0,013)$, conforme demonstrado no Gráfico 3.

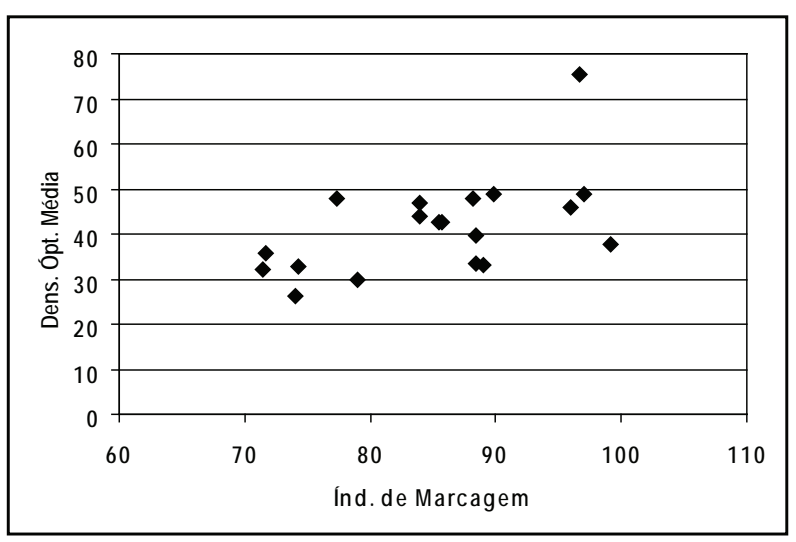

GRÁFICO 3 - Correlação entre o índice de marcagem e a densidade óptica média da caspase-3 


\section{DISCUSSÃO}

As caspases, pertencentes à família das cisteíno-proteases, estão diretamente associadas à apoptose. Estas enzimas possuem resíduo de cisteína em seu sítio ativo e clivam seus substratos quase que invariavelmente após resíduos de ácido aspártico.

As diversas caspases apresentam diferentes funções na coordenação da morte celular programada. As caspase-8 e 9 são as primeiras a serem ativadas, sendo denominadas iniciadoras. A caspase-3 é a responsável pela maioria dos efeitos celulares deletérios da apoptose, recebendo suporte de outras como a caspase-6 e a 7. Estas caspases são referidas como as de execução ou efetoras, e são ativadas proteoliticamente pelas iniciadoras ${ }^{15}$.

A caspase- 3 está relacionada à fragmentação do material genético, como por exemplo, através da ativação de fatores de fragmentação de DNA (DFFs) ${ }^{9}$. Ainda, a literatura aponta para a participação desta caspase no processo apoptótico induzido por diversos fatores em adenocarcinoma de cólon, como diferentes quimioterápicos ${ }^{1}$ e pode ocorrer retardo ou até inibição da apoptose por mutação ou ação farmacológica inibitória sobre as caspases ${ }^{3}$.

No entanto, existem conflitos na literatura. No trabalho de Dziegiel et al. ${ }^{5}$, foi demonstrada fraca correlação entre a quantidade de células expressando caspase-3 e a intensidade de apoptose em adenocarcinoma de cólon, havendo ainda variabilidade desta última entre os casos individuais. Desta forma, surge o questionamento se a simples detecção deste marcador seria um bom medidor da intensidade apoptótica.

A utilização de um anticorpo específico para caspase-3 ativada tem se mostrado técnica de maior eficiência para avaliar a intensidade de apoptose em tecidos humanos. Marshman et al..$^{12}$ encontraram correlação favorável entre a deteç̧ão da caspase-3 ativada e a identificação de células apoptóticas em ambos intestinos grosso e delgado em modelo animal experimental. $\mathrm{O}$ anticorpo monoclonal antiCPP32 utilizado neste trabalho reage com uma pró-enzima de $32 \mathrm{kDa}$ de uma variedade de tecidos humanos. Desta forma, é possível que a falta de correlação encontrada se deva a inespecificidade do anticorpo utilizado, que reagiria tanto com a pró-enzima (pró-caspase-3), quanto com a proteína clivada e ativa.

A expressão da caspase-3 $(85,24 \%$ de células positivas), avaliada pelo LI, não apresentou embasamento na literatura pesquisada, uma vez que são raros os trabalhos empregando imunoistoquímica para caspase-3 em adenocarcinoma colorretal.

No entanto, a observação de estudos utilizando a imunoistoquímica em outros tumores pode ajudar a elucidar algumas características da expressão de caspase-3 nas neoplasias. Outro estudo 9 ao constatar diminuição significativa da expressão de caspase-3 e da intensidade apoptótica em células de carcinoma hepatocelular, reforçam as evidências de que a progressiva resistência à apoptose é uma das principais características da maioria dos cânceres.

Neste trabalho, houve correlação entre o LI e a MOD da caspase-3. Considerando-se sua expressão citoplasmática, estes dados indicam que quanto maior o número de células positivas para a caspase-3, maior a intensidade de expressão deste marcador nos tecidos.

A identificação de novos marcadores nos cânceres colorretais, seria útil na prática clínica, pois permitiriam estratificar os pacientes de alto e de baixo risco. Seria assim possível obterem-se programas de rastreamento mais efetivos, os quais reduziriam os riscos da progressão tumoral, minimizariam o desconforto dos pacientes e teriam custos menores. Desde que o comportamento do câncer colorretal é altamente variável, é de grande importância encontrar marcadores prognósticos acurados, baseando-se no fato que há maior conscientização dos pacientes nos métodos de deteç̧ão que estão resultando em diagnósticos mais precoces de neoplasias menores.

Novas estratégias terapêuticas, tendo por base vias moleculares ou estruturas moleculares alteradas, serão mais eficientes e menos tóxicas que a quimioterapia ou a radioterapia, por possuírem alvo específico. A manipulação dos genes envolvidos na progressão da doença representa importante abordagem para intervenção terapêutica neste tipo de câncer (terapia gênica). $O$ desenvolvimento de novas abordagens para terapia gênica é crítico, já que não existe tratamento efetivo para pacientes em estágios avançados da doença.

Após décadas de tratamento oncológico, relativamente pouco específico e baseado unicamente na remoção (cirurgia) ou destruição (quimioterapia ou radioterapia) dos tumores, são finalmente vislumbrados tratamentos dirigidos contra alvos moleculares específicos, identificados a partir de estudos que permitem compreender a fisiopatologia do desenvolvimento e da progressão das neoplasias.

Novos estudos poderão ser conduzidos a partir dessas informações, não somente em relação às diversas vias moleculares envolvidas na gênese do tumor, como também em relação ao prognóstico, à resposta a tratamentos adjuvantes e, talvez, futuramente, à novas modalidades terapêuticas. Este estudo pode representar boa perspectiva futura, sendo que sua repetição com maior amostragem contribuiria para o esclarecimento da complexidade tanto do comportamento, quanto do tratamento do adenocarcinoma de cólon.

\section{CONCLUSÃO}

A intensidade da expressão de caspase-3 e o número de células expressando este marcador correlacionam-se positiva e significantemente. 
Gomes MJ, Ribas-Filho JM, Malafaia O, Czeczko NG, Ribas CAPM, Nassif PAN, Bittencourt LPM. Evaluation of caspase-3 markers expression in colorectal adenocarcinoma by a computadorized image analysis system. ABCD Arq Bras Cir Dig 2008;21(1):33-7

ABSTRACT - Background - Colorectal cancer is one of the most common causes of death for malignant neoplasm in the Occidental World, corresponding colorectal adenocarcinoma to represent more than $90 \%$ of malignant tumors in large bowel. Caspase- 3 cysteine protease, one of the most important enzymes related in the apoptosis process, may be used as a tumor marker. Aim - To identify and quantify Caspase-3 expression in colorectal adenocarcinoma samples and to correlate the marker expression using an image computerized analysis system. Method - Caspase-3 expressions were studied by immunohistochemistry in 55 colorectal adenocarcinoma sampled-tissues, prepared in paraffin blocks. SAMBA 4000 System was used for the immunostained tissues analysis. Microscopic evaluation was performed by the IMUNNO 4.00 software, which analyzed 8 to 10 fields in order to determine two parameters: Labeling Index (LI), indicating the percentage of cells specifically stained by immunohistochemistry, and Mean Optical Density (MOD), representing enhance intensity, measured by positive pixels. For the statistical analysis, t-Student test and Pearson coefficient verified the possible correlation concerning LI and MOD. Results - All samples presented positivity for Caspase-3 expression (LI 85,24\% $\pm 8,71 \%$ positive cells). Caspase- 3 expression revealed statistically significance correlation between LI and MOD $(P=0,013)$. Conclusions - The intensity of Caspase-3 expression and the number of positive cells expressing such a marker showed a positive and significant correlation.

HEADINGS - Colorectal adenocarcinoma. Ki-67. Caspase-3. SAMBA 4000.

\section{REFERÊNCIAS}

1. Adachi Y, Taketani S, Oyaizu H, Ikebukuro K, Tokunaga R, Ikehara S. Apoptosis of colorectal adenocarcinoma induced by $5-\mathrm{FU}$ and/or IFN-gamma through caspase 3 and caspase 8. Int J Oncol 1999;15(6):1191-6.

2. Bancroft JD, Stevens A. Theory and practice of histochemical techniques. Edinburgh: Churchill Livingstone1992. 677 p.

3. Barcinski MA. Morte celular. In: Ferreira CG, Rocha JC. Oncologia molecular. São Paulo: Atheneu, 2004.57-63 p.

4. Cohen GM. Caspases: the executioners of apoptosis. Biochem J 1997;326(1):1-16.

5. Dziegiel P, Dumanska M, Forgacz J, Wojna A, Zabel M. Intensity of apoptosis as related to the expression of metallothionein (MT), caspase-3 (cas-3) and $\mathrm{Ki}-67$ antigen and the survival time of patients with primary colorectal adenocarcinomas. Rocz Akad Med Bialymst 2004;49(1):5-7.

6. Instituto Nacional de Câncer. Estimativa 2006: Incidência de câncer no Brasil. Rio de Janeiro, 2005

7. Jemal A, Murray T, Ward E, Samuels A, Tiwari RC, Ghafoor A, Feuer EJ, Thun MJ. Cancer statistics, 2005. CA Cancer J Clin 2005;55(1):10-30.

8. Landis SH, Murray T, Bolden S, Wingo PA. Cancer statistics, 1998. CA Cancer J Clin. 1998;48(1):6-29.

9. Liu X, Zou H, Slaughter C, Wang X. DFF, a heterodimeric protein that functions downstream of caspase-3 to trigger DNA fragmentation during apoptosis. Cell $1997 ; 89(2) 175-84$
10. Mady HH, Melhem MF. FHIT protein expression and its relation to apoptosis, tumor histologic grade and prognosis in colorectal adenocarcinoma: an immunohistochemical and image analysis study. Clin Exp Metastasis 2002;19(4):351-8.

11. Malafaia O, Moraes RS, Coelho JCU, Ribas-Filho JM, Nassif PAN, Czeczko AEA. Tumores carcinóides do tubo digestivo. In: Habr-Gama A, Gama-Rodrigues J, Cecconelo I, Zilberstein B, Saad WA, Bresciani C, Kiss DR, Cunha JEM, Bocchini S. Atualização em cirurgia do aparelho digestivo e coloproctologia. São Paulo: Frôntis, 2005.159-167 p.

12. Marshman E, Ottewell PD, Potten CS, Watson AJ. Caspase activation during spontaneous and radiation-induced apoptosis in the murine intestine. J Pathol. 2001;195(3):275-6.

13. Ribas CAPM. Avaliação da presença e quantificação em porcentagem da galectina-1 no esôfafo de Barret sem displasia, através de sistema informatizado de análise de imagem. Curitiba, 2000. 76 f. Dissertação (Mestrado em Medicina Interna). Setor de Ciências da Saúde, Universidade Federal do Paraná.SPENCER, M. Fundamentals of light microscopy. Cambridge: Cambridge University Press 1982.93 p.

14. WolfBB, Schuler M, Echeverri F, Green DR. Caspase-3 Is the Primary Activator of Apoptotic DNA Fragmentation via DNA Fragmentation Factor-45/Inhibitor of Caspase-activated DNase Inactivation. J Biol Chem. 1999;274(43):30651-6.

15. Zimmermann KC, Green DR. How cells die: apoptosis pathways. J Allergy Clin Immunol. 2001;108(4 suplemento):99-103. 